\title{
Desenvolvimento social e alívio da pobreza no discurso do Banco Mundial: implicaçóes para as políticas de formaçáo de professores ${ }^{1}$
}

\author{
Anibal Correia Brito Neto ${ }^{2}$ \\ https://orcid.org/0000-0001-6618-6299
}

\section{Resumo}

Em face da necessidade de readequação da governabilidade neoliberal, cuja vertente ortodoxa mostrou os seus limites, o Banco Mundial precisou subordinar, analítica e programaticamente, a política de alívio da pobreza à perspectiva de liberalização econômica, o que implicou em uma maior prioridade concedida ao fenômeno educacional e, consequentemente, à figura do professor. Nesse contexto, o estudo em tela buscou sistematizar e discutir as principais proposiçóes do Banco Mundial para a especificidade da formação docente na atualidade. Por meio da análise conceitual dos documentos do Banco sobre o tema educacional, foi possível revelar que por trás do discurso afável da busca pelo desenvolvimento social e do alívio da pobreza está encoberto a inversão ideológica entre aquilo que seria determinante e determinado no que se refere à dinâmica social, o uso funcional à logica do capital da categoria aprendizagem e o predomínio das pedagogias do aprender a aprender. Nesse sentido, conclui-se que o enaltecimento do tema docente, em especial da formação de professores, está relacionado com a possibilidade de o professor operar, no âmbito escolar e sob o ardil do discurso de justiça social, a reprodução tanto das condiçôes técnicas quanto ético-políticas necessárias à manutenção da ordem capitalista.

Palavras-chave: Política educacional, Formação de professores, Banco mundial, Justiça social.

\section{Social development and poverty alleviation in the World Bank's discourse: implications for teacher education policies}

\footnotetext{
Abstract

In view of the need to readjust neoliberal governance, whose orthodox dimension has shown its limits, the World Bank had to subordinate itself, analytically and programmatically, to the policy of poverty alleviation of the perspective of economic liberalization, which implied into

${ }^{1}$ Este artigo é derivado e adaptado da Tese de Doutorado intitulada "Política Nacional de Formação de Professores no Brasil (2003-2016) como expressão da governança global” (BRITO NETO, 2018), defendida no Programa de Pós-Graduação em Educação da Universidade Federal de Santa Catarina, a qual contou com financiamento da Coordenaçáo de Aperfeiçoamento de Pessoal de Nível Superior (Capes) e do Governo do Estado do Pará.

2 Doutor em Educação pela Universidade Federal de Santa Catarina (UFSC), com período sanduíche na University of Edinburgh (Escócia). Professor Assistente IV da Universidade do Estado do Pará (UEPA). Líder do grupo de pesquisa Ressignificar/UEPA - Experiência Inovadoras na Formação de Professores e Prática Pedagógica. Lattes: http://lattes.cnpq.br/3700657249309537. E-mail: anibal.neto@uepa.br.
} 
a higher priority to the educational phenomenon and, consequently, to the figure of the teacher. In this context, the study on sight sought to systematize and discuss the main proposals of the World Bank for the specificity of teaching formation nowadays. Through the conceptual analysis of the Bank's documents about the educational topic, it was possible to reveal that, behind the affable discourse of the search for development and the poverty alleviation, the ideological inversion between what would be determinant and determined when it comes to social dynamics, the functional use of the capital of the learning category and the predominance of learn to learn pedagogies. In this way, it is concluded that the enhancement of the teaching theme, especially of teaching formation, is related to the possibility of the teacher operating, in the school environment and under the ruse of social justice, the reproduction of both technical and ethico-political conditions necessary to the maintenance of capitalist order.

Keywords: Education policy, Teachers education, World bank, Social justice.

\section{Introdução}

Caracterizado por uma trajetória que combina "dinheiro, prescriçóes políticas e conhecimento econômico", com o fim último de assegurar a implementação da sua agenda política nos Estados-nacionais (PEREIRA, 2010), não resta dúvida sobre a notoriedade assumida pelo Banco Mundial (BM) na contemporaneidade, não apenas no âmbito político e financeiro, mas também no domínio intelectual e educacional.

Em decorrência das novas coordenadas estratégicas, evidenciadas nas décadas de 1980 e 1990, as quais remodelaram a intervenção do Banco em face da preocupação com os "custos sociais" do ajustamento estrutural neoliberal, Pereira (2010) esclarece que o BM passou a conjugar e, ao mesmo tempo, subordinar, analítica e programaticamente, a política de alívio da pobreza à liberalizaçáo econômica.

Trata-se, portanto, da incorporação no binômio ajuste/compensação focalizada do processo de neoliberalização da política social, de intervençóes compensatórias tais como o acesso aos "serviços sociais básicos (sobretudo saúde, educação primária e planejamento familiar), sob a forma de redes de segurança (safety nets) e programas para a formação de 'recursos humanos'” (PEREIRA, 2010, p. 280).

De acordo com Leher (1999), estaria nesse contexto, em especial na necessidade de articular as prioridades educacionais às econômicas, bem como de contenção das tensóes provenientes do desemprego e das questóes mais gerais ligadas à pobreza, como a insegurança e o clima desfavorável aos negócios, a chave explicativa para a compreensão da centralidade adquirida pela educação no discurso do BM desde o final da década de 1980. 
Ainda em Leher (1999) é possível apreender que os pressupostos das reformas educacionais sob a batuta do BM nos anos 1980-1990 pretendiam legitimar a exclusão estrutural e, assim, assegurar as condições de governabilidade, para tanto, lidavam com as contradiçôes da segregação difundindo a premissa de que o capitalismo somente é justo com os que se qualificavam corretamente.

Nessa perspectiva, Torres (2009) esclarece que as prioridades e estratégias para a educação, em termos de alocação de recursos no "pacote de reformas educativas" desse período, se focaram em três aspectos como merecedores de um maior espaço na tomada de decisóes dos sistemas educacionais: o aumento do tempo de instrução, o oferecimento de livros didáticos e o melhoramento do conhecimento dos professores, privilegiando, sobretudo, a capacitação em serviço sobre a formação inicial, e estimulando as modalidades a distância.

Com a transição para o Século XXI, Decker (2015) analisou que a escola e o professor passaram a ser responsabilizados, com maior ênfase, pela aprendizagem dos estudantes e, consequentemente, tidos como agentes determinantes para a efetivação dos prenúncios econômicos e sociais. Nesse novo contexto, Decker (2015) adverte que o BM tem constituído um discurso em prol daquilo que a própria autora nomeou de "entronização da sala de aula”, isto é, trata-se de uma inversão operada pelo Banco na base da formação - da universidade para o treinamento em serviço - orientado para e pela sala de aula, com o propósito de limitar o trabalho educativo e engendrar uma prática "reduzida às competências técnicas, metodológicas, pragmáticas, utilitaristas, instrumentais” (DECKER, 2015, p. 215).

Portanto, no sentido de dar prosseguimento às análises de Torres (2009) e Decker (2015), as quais permitiram a visualização panorâmica da agenda do BM para o campo das políticas de formação de professores, o estudo em tela visa sistematizar e discutir as principais proposiçóes do BM para esse campo na atualidade, em especial, as implicaçóes da Estratégia para a Educação 2020 do BM, nomeada Aprendizagem para todos: investir nos conhecimentos e competências das pessoas para promover o desenvolvimento (BANCO MUNDIAL, 2011), para a especificidade da formação docente.

$\mathrm{O}$ estudo se configura como documental, em que procedemos as técnicas da análise conceitual de documentos, desenvolvida pelo Grupo de Estudos sobre Política Educacional e Trabalho da Universidade Federal de Santa Catarina (GEPETO/UFSC), a qual se volta para decifrar as mensagens implícitas e explícitas nos documentos de políticas, alertando-nos para a forma contraditória com que os "conceitos e argumentos da reforma" são 
apresentados e utilizados nos textos (SHIROMA; CAMPOS; GARCIA, 2005).

Para este fim, operamos a partir do website institucional BM Open Knowledgde Repository, o levantamento dos principais documentos políticos educacionais internacionais no domínio da Estratégia para a Educação 2020 do BM, são eles: 1) "Aprendizagem para todos" (BANCO MUNDIAL, 2011), o resumo executivo em português do relatório que expõe as bases da Estratégia para a Educação 2020 do BM, que tem como lema principal a 'aprendizagem para todos'. Segundo o documento, pautou-se em consultas sobre o que funciona em educação em mais de 100 países; 2) What matters most for teacher policies (BANCO MUNDIAL, 2013), produzido pelos membros da equipe principal da iniciativa SABER-Teachers, o documento se propóe a oferecer um quadro para analisar as políticas de professores nos sistemas educacionais em todo o mundo, no sentido de subsidiar a tomada de decisão baseada nas evidências dos sistemas de alto-desempenho. 3) "Professores Excelentes" (BRUNS; LUQUE, 2015), destacado como as últimas evidências e experiências práticas com reformas das políticas docentes. Trata-se de uma pesquisa de três anos que reuniu observação de mais de 15.000 professores em sala de aula; e 4) World Development Report 2018 (BANCO MUNDIAL, 2018), considerada a publicação anual mais importante do Banco, esta é a primeira vez, em 40 ediçóes, que o Relatório sobre o Desenvolvimento Mundial (RDM) aborda a questão educacional na totalidade da publicação.

\section{Os contornos da estratégia para Educaçáo 2020 do Banco Mundial}

O ponto de partida da Estratégia para Educação 2020 é a retórica narrada pelo Banco Mundial (2011, p. 3) de que o "crescimento, desenvolvimento e redução da pobreza dependem dos conhecimentos e qualificaçóes que as pessoas adquirem". Contudo, o Banco afirma que se por um lado o mundo mudou, revelando incríveis avanços tecnológicos e o desejo de muitas naçóes por aumentar a sua competitividade, pelo outro, o acesso de milhóes de crianças adicionais às escolas tem contrastado com as taxas em alguns países de $25 \%$ a $50 \%$ dos jovens formados no ensino primário sem conseguir ler uma simples frase.

Consequentemente, o Banco Mundial (2011) defendeu que sua estratégia para a suposta promoção do desenvolvimento nos próximos 10 anos não estaria pautada nos anos que o indivíduo passa sentado numa sala de aula, 
mas naquilo "que as pessoas aprendem, dentro e fora da escola, desde o jardimescola até o mercado de trabalho" (BANCO MUNDIAL, 2011, p. 1, grifo do autor.). Para tanto, sustentou uma Estratégia com foco na Aprendizagem para Todos, estruturada em três pontos considerados essenciais: investir cedo, desde a infância; investir com inteligência, priorizando aquelas medidas que provaram contribuir para a aprendizagem; e investir em todos, com foco nas meninas, deficientes, minorias etnolinguísticas e populaçôes desfavorecidas. Segundo o BM, tal Estratégia estaria em sinergia com as suas prioridadeschave, que seriam: "ter os pobres e vulneráveis como objetivo, criar oportunidades de crescimento, promover açóes coletivas globais e reforçar a governação" (BANCO MUNDIAL, 2011, p. 13).

Para Pronko (2014), o artifício utilizado pelo BM de dar destaque à aprendizagem em sua Estratégia estaria relacionado a duas questóes essenciais. A primeira estaria nas possibilidades colocadas por este alargamento conceitual para a valorização de outros processos e espaços formativos que não estivessem ligados exclusivamente ao sistema público de ensino, mas também às difusas oportunidades de aprendizagem disseminadas na vida social, em especial, na esfera produtiva, ampliando, assim, o papel do setor privado na educaçáo, enquanto a segunda estaria voltada à articulação entre as demandas produtivas e os processos educativos. Pronko (2014) esclarece que a concepção de aprendizagem defendida pelo BM fortalece a noção de competências ligadas ao 'saber fazer', em detrimento das certificaçôes educacionais. Tal medida, portanto, se coaduna com a adoção pelo Banco da ideia de crescimento econômico como parâmetro de medida para informar o nível de desenvolvimento de determinada nação. Argumenta o $\mathrm{BM}$, em meio a redentoras evidências, que o nível de competências de uma força de trabalho é mais promissor que as médias de escolaridade para fins de crescimento econômico.

Somado a isso, Decker (2015) analisa que na busca por subordinar a educação à sua lógica de desenvolvimento global, os documentos estratégicos do BM têm revisitado permanentemente a teoria do capital humano, logo, a adoção da perspectiva da aprendizagem estaria inscrita neste horizonte de desenvolvimento de competências necessárias à força de trabalho, em consonância com a divisão internacional do trabalho, favorecendo, dessa forma, "uma educação meritocrática, centrada no indivíduo, instauradora da competitividade e da flexibilidade, orientada por uma formação estritamente pragmática em consonância com o mercado" (DECKER, 2015, p. 83).

Recentemente, em uma açáo que ratifica a importância da estratégia educacional para a intervenção do $\mathrm{BM}$, foi lançada a 40ª edição do Relatório 
sobre o Desenvolvimento Mundial (RDM) - um guia de grande influência entre Organizaçôes Internacionais Multilaterais, que combina análises e recomendaçóes sobre um aspecto específico considerado importante para o desenvolvimento e que tem sito utilizado amplamente pelo BM para subsidiar os processos políticos de tomada de decisão - com ênfase específica na questão $\mathrm{da}$ "aprendizagem para realizar a promessa educacional" (BANCO MUNDIAL, 2018). Apesar do RDM 1998/1999 e o RDM 2007 ter abordado de forma transversal a temática educacional a partir da formulaçáo sobre "conhecimento para o desenvolvimento" (BANCO MUNDIAL, 1998) e "desenvolvimento e a próxima geração" (BANCO MUNDIAL, 2006), respectivamente, podemos dizer que é somente com o RDM 2018 que a educação figura como tema central da publicação. Esta inflexão, segundo os critérios apontados pelo próprio presidente do BM à época, Jim Yong Kim, somente vem ratificar a lógica sinalizada por Pronko (2014) e Decker (2015). Vejamos o trecho do discurso de Kim no prefácio do RDM 2018:

Em suma, a educaçáo promove poderosamente os objetivos estratégicos indissociáveis do Grupo Banco Mundial: acabar com a pobreza extrema e aumentar a prosperidade compartilhada. Dado que os estudantes de hoje serão cidadãos, líderes, trabalhadores e pais de amanhã, uma boa educação é um investimento com benefícios duradouros.

Mas fornecer educação não é suficiente. O que é importante, e o que gera um retorno real do investimento, é aprender e adquirir habilidades. Isto é o que realmente constrói o capital humano. Como o Relatório sobre o Desenvolvimento Mundial deste ano documenta, em muitos países e comunidades, a aprendizagem não está acontecendo. Escolarização sem aprendizagem é um desperdício terrível de recursos preciosos e de potencial humano.

Pior, é uma injustiça. Sem aprender, os estudantes estarão presos em vidas de pobreza e exclusão, e as crianças as quais as sociedades falham mais são aquelas que mais precisam de uma boa educação para ter sucesso na vida. As condiçóes de aprendizagem são quase sempre muito piores para os desfavorecidos, assim como os resultados de aprendizagem. Além disso, muitas crianças ainda não estão frequentando a escola. Esta é uma crise moral e econômica que deve ser abordada imediatamente. (BANCO MUNDIAL, 2018, p. vi, tradução nossa).

Portanto, recoberto pela cantilena moralista e defensora dos 'grupos desfavorecidos' (crianças pobres, meninas, crianças com deficiência, minorias 
étnicas) - com o fim de valer-se do recurso da comoção para arrebanhar audiência e adeptos - o discurso ao longo do relatório é incisivo na denúncia das injustiças e do fracasso moral e econômico decorrente da crise de aprendizagem. O RDM 2018 assevera que a baixa aprendizagem, vivida particularmente nos países de 'baixa e média renda', pode ser evitada, para tanto, é necessário tomar como prioridade a implementação coordenada de políticas e a reforma do sistema, tomando por base as evidências, o que segundo Pronko (2014, p. 107), tem se tornado um mantra para as Organizaçôes Multilaterais, mas que no fundo tais evidências seriam, na maioria das vezes, "correlaçóes simples entre indicadores quantitativos definidos por algum grupo de expertos como relevantes para influenciar a orientação de políticas setoriais específicas".

Segundo o documento, a preocupante crise de aprendizagem estaria expressa em três dimensóes. A primeira seria a própria insuficiência dos resultados da aprendizagem, isto é, as expectativas de aprendizagem depositadas no processo de escolarização com frequência não ocorrem, dessa forma, combina-se baixos níveis de aprendizagem, elevada desigualdade e avanços geralmente lentos. A segunda seria aquela representada por 'causas imediatas', visíveis no próprio sistema educativo, que se revelam de quatro formas: 1) crianças mal preparadas devido as difíceis condiçôes associadas à pobreza e jovens afetados pelas barreiras financeiras e dimensóes sociais da exclusão; 2) professores muitas vezes não possuem habilidades ou motivaçáo para ensinar de forma eficaz; 3) recursos materiais e tecnológicos constantemente não alcançam as salas de aula ou quando alcançam, não afetam a aprendizagem; 4) gestão ineficaz dos estabelecimentos educativos, somado a uma governança que carece de suficiente autonomia para tomada de decisóes. A terceira seria compreendida em uma perspectiva sistêmica, onde as complexidades técnicas e os interesses concorrentes de forças políticas têm se conformado como as causas mais profundas de um presumível desalinhamento dos sistemas educacionais em relação ao propósito maior da aprendizagem. Em síntese, os experts do Banco afirmam que a combinação desses fatores tem inviabilizado que os sistemas educacionais equipem os alunos para que estes possam levar uma "vida saudável, produtiva e significativa", visto que não conseguem garantir aos alunos as competências básicas este fim, tais como:

Aprender como interpretar muitos tipos de passagens escritas - de rótulos de medicamentos a ofertas de emprego, de extratos bancários a grandes obras literárias. Eles têm que entender como os números 
funcionam para que possam comprar e vender nos mercados, definir orçamentos familiares, interpretar acordos de empréstimo, ou escrever códigos de engenharia de software. Eles precisam do raciocínio complexo e da criatividade que se desenvolvem a partir dessas habilidades básicas. E necessitam das competências socioemocionais tais como a perseverança e a capacidade para trabalhar em equipe - que os ajudem a adquirir e aplicar essas capacidades básicas e outras habilidades. (BANCO MUNDIAL, 2018, p. 4, tradução nossa).

Diante desta caracterização, a equipe de experts do RDM 2018 indica ser somente possível reverter a propalada crise de aprendizagem com os sistemas educacionais adotando definitivamente a aprendizagem como um 'compromisso de todos', utilizando-a, portanto, como guia e métrica da realização da promessa educacional. Para tanto, a equipe do BM resumiu esta empreitada na consigna 'todos pela aprendizagem', a qual envolveria três estratégias complementares e interdependentes, a saber: 1) avaliar a aprendizagem para tornar a sua melhoria um objetivo sério, medindo e qualificando o seu acompanhamento, a fim de utilizar os seus resultados para guiar as medidas a serem adotadas; 2) atuar por meio de evidências de experiências exitosas no aperfeiçoamento dos resultados da aprendizagem, de forma a orientar a inovação e a prática, além de fazer com que as escolas trabalhem em função de todos os alunos; e 3) alinhar os atores, estabelecer coalizóes e enfrentar os obstáculos de ordem técnica e política com o propósito de garantir que o sistema funcione integralmente a favor do desenvolvimento da aprendizagem.

De modo mais detido à questão docente, o RDM 2018 destinou um capítulo específico para desenvolver a ideia de que as "habilidades e motivação dos professores são importantes”. O centro da argumentação sobre este tópico foi de que o professor é o "ingrediente mais fundamental" à aprendizagem depois do próprio aluno, visto ser o último o centro de todos os esforços. Tal assertiva tem estado presente em diferentes documentos, seja do BM ou de diversas outras Organizaçóes Multilaterais, motivo pelo qual nos deteremos, na próxima seção, à especificidade docente no âmbito das publicações analisadas neste estudo.

\section{O professor e a sua formaçáo na agenda do Banco Mundial}

Inicialmente vale resgatar dois excertos que expressam categoricamente a linha discursiva que o BM tem construído quando este tem tratado da 
questão docente no último período. O primeiro é de Bruns e Luque (2015, p. 7), experts do Banco, que declaram que "a capacidade dos professores de assegurar que seus estudantes aprendam é o elemento sine qua non para os estudantes e os países colherem os benefícios econômicos e sociais da educação". O segundo é um trecho de BM (2013, p. 5), o qual aponta que “[...] uma série de estudos tem revelado que a eficácia do professor é o preditor mais importante baseado na escola sobre a aprendizagem dos alunos e que vários anos consecutivos de ensino excepcional podem compensar os déficits de aprendizagem dos estudantes em desvantagem”.

Conforme esclarece Banco Mundial (2018), os professores conformam o maior item orçamentário educacional e absorvem, somente na América Latina, 4\% do Produto Interno Bruto (PIB) da região, segundo os dados de Bruns e Luque (2015). De acordo com a dupla de economistas do BM, são mais de sete milhóes de professores a entrarem em salas de aula diariamente neste território, perfazendo $4 \%$ da força de trabalho total da região e mais de $20 \%$ dos trabalhadores técnicos e profissionais. Contudo, ambos estudos são categóricos em defender que a insuficiência da qualidade docente tem sido um forte impeditivo para a promoção da tão enfatizada aprendizagem.

Se, por um lado, Banco Mundial (2018) afirma que muitos professores estão em sala de aula com pouco domínio sobre a matéria a ser ensinada, em especial, no atendimento às crianças pobres, por outro lado, Bruns e Luque (2015) declaram que os professores na América Latina e Caribe apresentam fraco domínio acadêmico e dispóem de práticas ineficazes em sala de aula, revelando-se como "o fator limitante sobre o progresso da educação na região e, por conseguinte, sobre a contribuição da despesa nacional com educaçáo para a redução da pobreza e prosperidade compartilhada" (BRUNS; LUQUE, 2015, p. 2).

Portanto, com base nas tão propaladas 'evidências' nesta área, o RDM 2018 recomenda três princípios para alcançar o sucesso da aprendizagem através dos professores, a saber: a promoção do ensino ao nível de habilidades dos alunos; o aumento da motivação e incentivo dos professores; e a oferta de uma formação de professores eficaz. Já para Bruns e Luque (2015), três passos seriam fundamentais para obtenção de um corpo docente de 'alta qualidade': recrutamento, capacitação e motivação de melhores professores. Por seu turno, o Banco Mundial (2013a) trabalha com a indicação de oito metas políticas para que os sistemas disponham de professores eficazes: 1) definição de standards e normas; 2) mecanismos para atrair os melhores para o ensino; 3) oferta de formação e experiências úteis; 4) correspondência entre as competências dos professores e as necessidades dos alunos; 5) investimento no 
desenvolvimento de diretores e habilidades de lideranças; 6) mecanismos de avaliação do desempenho docente e da aprendizagem do aluno; 7) apoio aos professores para melhorar a instrução; e 8) medidas de motivação ligada ao desempenho docente.

Sobre as recomendações voltadas à especificidade da formação de professores, o RDM 2018 indica um "princípio síntese” para uma formação de professores eficaz - seja no desenvolvimento profissional em serviço [inservice professional development] ou como ponto de partida para uma melhoria da formação inicial ou pré-serviço [preservice training]: a defesa de uma formação direcionada e repetida individualmente, com treinamento [coaching] na forma de acompanhamento em sala de aula, frequentemente em torno de uma técnica pedagógica específica para uma área temática, por exemplo, como ensinar uma classe de matemática efetivamente.

Em sentido semelhante, Bruns e Luque (2015) sugerem que os baixos resultados da aprendizagem dos alunos na América Latina e Caribe estariam relacionados com a dificuldade dos professores em envolverem os alunos no processo de aprendizagem, o que implicaria, para tanto, que os programas de formação de professores, tanto "anteriores ao serviço quanto em serviço", garantissem o reconhecimento pelos professores da "[...] importância de atrair todos os alunos para o processo de aprendizagem; estar equipados com uma série de estratégias de ensino para conseguir isso; e chegar à escola todos os dias preparados para usar essas estratégias todos os minutos do tempo de aula e com eficácia” (BRUNS; LUQUE, 2015, p. 18).

Segundo o Banco Mundial (2013), a educação formal e a formação prática que os indivíduos devem realizar para tornarem-se professores das escolas públicas influenciam no status social da profissão, na motivação e na decisão sobre tornar-se professor como primeira opção e, fundamentalmente, nas habilidades e nos conhecimentos que os professores levariam para a sala de aula, portanto, o Banco indica que:

[...] equipar os professores com as habilidades que precisam para ter sucesso na sala de aula é crucial. Os professores precisam de conhecimentos pedagógicos e da matéria, bem como habilidades de gerenciamento de sala de aula e muita prática de ensino para terem sucesso em sala de aula. (BANCO MUNDIAL, 2013, p. 27).

Essa diretriz matricial para a formação docente, presente extensivamente nos documentos do Banco, que restringe o abrangente e complexo campo formativo a um mero treinamento prático-instrumental, 
confinado ao ambiente restrito da sala de aula, ratifica, no fundo, a precisão de Decker (2015) ao caracterizar como linha política do BM para a docência, a ideia de um professor como "aprendiz eternamente treinável", que ao se deparar com o processo de "entronização da sala de aula", tem suas possibilidades formativas reduzidas ao simples manuseio de procedimentos e técnicas capazes de desenvolver nos estudantes as competências requeridas pelo cambiável mercado de trabalho.

É do próprio estudo de Decker (2015) a ilação de que esta diretriz formativa, pautada em um modelo tecnicista e que negligencia a reflexão teórica, estaria associada ao que Moraes (2009) denominou no campo filosófico, de "ceticismo epistemológico e relativismo ontológico" (MORAES, 2009 apud DECKER, 2015, p. 40). As consequências de tais orientações estariam na promoção de um "apartheid entre teoria e prática que não encaminha a apreensão complexa da totalidade em suas dinâmicas relaçóes com as dimensôes políticas, econômicas, culturais e social da realidade objetiva" (DECKER, 2015, p. 40).

Esta concepção fundamental do BM sobre a formação docente vai estar espraiada em outras indicaçóes neste campo, como por exemplo na histórica polarização promovida pelo Banco e denunciada por Torres (2009) entre formação inicial e treinamento em serviço. No RDM 2018 há uma clara tentativa de convencer, por meio das supostas 'experiências exitosas', o papel secundário que deve cumprir a formação inicial em relação ao desenvolvimento profissional em serviço. Com base na experiência da Índia, o relatório defendeu que a combinação de uma breve formação inicial, seguida do acompanhamento contínuo dos professores comunitários, ao longo de todo o ano, foi fator de grandes ganhos na aprendizagem dos alunos. $\mathrm{Na}$ experiência dos EUA, os experts buscaram demonstrar que os programas que ignoram a formação inicial e propóem 'rotas alternativas' ao ensino, tal como o famoso Teach for America e o programa community-teacher, não reduziram a aprendizagem dos alunos, o que levou o Banco Mundial (2018, p. 133) a concluir que:

Este resultado questiona o valor da formaçáo inicial. Contudo, as rotas alternativas frequentemente substituem a formaçáo inicial por uma seleçâo mais cuidadosa de professores (tal como no Teach for America) ou por contratos mais orientados para o desempenho (tal como aqueles para professores comunitários contratados). 
Portanto, como se pode visualizar, a estratégia do BM neste quesito permanece inalterada daquela dos anos 1980-1990 e, então, o treinamento em serviço continua a ser indicado no RDM 2018 como a 'esperança' de melhores ganhos na aprendizagem, conforme sustentam as evidências dos 'países de alta-renda', enquanto a formação inicial é tida como objeto de "evidências controversas e limitadas". O RDM 2018 argumenta ainda que os desafios político-econômicos para a melhoria da formação inicial podem ser maiores do que o treinamento em serviço, logo, o modelo de sucesso estaria no desenvolvimento profissional eficaz, que teria como aspectos-chave a praticidade (com base em métodos concretos utilizados em sala de aula, em oposição aos constructos teóricos), a especificidade (com base em uma pedagogia específica para o ensino de uma área disciplinar) e a continuidade (com base em apoio significativo e contínuo aos professores e não em oficinas isoladas).

Em decorrência deste modelo almejado apresentar, presumivelmente, implicações financeiras para os países que optarem pela sua implementação, os experts do RDM 2018 que, ao longo do relatório, se vangloriavam da opçáo pelo lema 'todos pela aprendizagem' e condenavam as disparidades remanescentes nos sistemas educacionais, principalmente, por afetar de forma exponencial os 'grupos desfavorecidos', agora, em face do dilema orçamentário de que muitos países não conseguiriam garantir a implantação deste modelo formativo de modo abrangente, indicam, sem hesitação, que "um país enfrentando este dilema pode ser melhor atendido ao oferecer treinamento de alta qualidade em etapas, em vez de treinamento ineficaz para todos a curto prazo" (BANCO MUNDIAL, 2018, p. 133), revelando, assim, o perfil histórico desta Organização, como fiel promotora do "apartheid educacional" (LEHER, 1999).

Em articulação com a prioridade outorgada a esta etapa formativo, Banco Mundial (2013) defende que o desenvolvimento profissional é um componente essencial, com incidência na melhoria do desempenho dos alunos, bem como no desempenho, motivação e perfil dos professores e, em especial, para aqueles professores com dificuldades (informados através das avaliaçóes de desempenho), aos quais se pode disponibilizar as ferramentas de que os mesmos precisam para melhorar. Para tanto, o Banco indica a necessidade desta etapa formativa enfatizar a mudança pedagógica e a melhoria da instrução, com demonstração de como os professores podem implementar essas práticas. Recomenda, ainda, que tais atividades sejam de tipo colaborativa, de forma que se promova o compartilhamento de melhores 
práticas e investigação sobre métodos de ensino ao nível escolar, tais como redes de professores, programas de mentoria e sistemas de estudo de liçóes.

Neste domínio, Bruns e Luque (2015) sugerem quatro estratégias orientadoras para organizar os programas de desenvolvimento profissional nos países da América Latina e Caribe: 1) treinamento para que os professores provenientes de "ambientes de baixa capacidade" possam utilizar estratégias de ensino e materiais bem-definidos diariamente na implementação do currículo; 2) treinamento para que os professores possam preencher lacunas anteriores ou aprofundar os conhecimentos sobre as matérias que eles ensinam e como ensiná-las de maneira eficaz; 3) treinamento para que os professores possam ampliar sua eficácia em sala de aula por meio de planejamento cotidiano, uso eficiente do tempo de aula, estratégias para o envolvimento dos alunos e técnicas de ensino eficazes; e 4) oportunidade de colaboração dentro das escolas ou entre escolas por meio de observação e aprendizagem recíproca da prática em sala de aula, desenvolvimento de currículos, estratégias de avaliação dos alunos, pesquisa e demais atividades que promovam o desenvolvimento profissional e a qualidade do ensino, como estratégia de melhor custo-eficácia para melhorar os resultados escolares.

Quanto à organização destas atividades, o Banco Mundial (2013) traz algumas questóes sobre a oferta, o financiamento e a determinação dos conteúdos destas atividades. Segundo o documento, as características de descentralização e privatização da oferta poderiam fomentar a competição entre as instituiçóes envolvidas neste provimento e implicar na melhoria da qualidade dos serviços disponíveis e na adequação às necessidades locais e específicas dos professores, porém, a descentralização traz a dificuldade do monitoramento da qualidade e dificulta que o governo central possa aproveitar tais atividades para promover os objetivos e políticas educacionais nacionais, além do que o financiamento descentralizado do desenvolvimento profissional pode deixar os professores das regióes mais pobres em desvantagem.

Por outro lado, Bruns e Luque (2015) advertem que preparar programas de desenvolvimento como os referidos acima não seria tarefa fácil, principalmente devido à frágil relação entre os Ministérios da Educação e os Departamentos de Educação das Universidades nos países da América Latina e Caribe, o que torna os últimos mal preparados para responder a tais necessidades; nesse sentido, indicam aquilo que os dois experts consideram como medidas inovadoras, entre as quais, a criação de institutos de formação de professores no serviço para controlar diretamente o conteúdo e a implementação do desenvolvimento profissional dos professores e, ainda: 
Usar os dados de avaliação de professores para determinar prioridades de capacitação; explorar parcerias com organizaçóes não governamentais, centros de estudo e outros provedores que operam fora dos departamentos de educaçáo das universidades; e investir em avaliação rigorosa pelo menos das iniciativas de capacitação mais importantes ajudarão a fazer investimentos mais produtivos nessa área, o que é essencial para acelerar o aumento do calibre do corpo docente atual. (BRUNS; LUQUE, 2015, p. 39).

Mesmo com a propensão histórica do BM pela formação de professores realizada no formato de capacitação em serviço, em detrimento dos programas pré-serviço, o reconhecimento de que a formação inicial permanece importante para a maioria dos sistemas educacionais tem obrigado os experts do BM a discutir e até mesmo reconhecer que a formação inicial seria importante no fornecimento de habilidades básicas aos professores, desde que vinculada a proposta de "treinamento mais prático" (BANCO MUNDIAL, 2018). Bruns e Luque (2015) ratificam este preceito quando sugerem como medida para elevação da qualidade da formação de professores que a formação pré-serviço esteja focada no trabalho que os professores enfrentarão nas salas de aula, pois conforme argumentam, tal modelo está subsidiado por 'evidências' que demonstraram a obtenção de professores principiantes mais eficazes e uma aprendizagem mais elevada para os estudantes.

Portanto, para garantir que tal característica seja, de fato, adotada pelos sistemas educacionais, Bruns e Luque (2015) sugerem que diante da autonomia das universidades em definir os seus programas formativos, o uso criativo de programas de financiamento competitivo poderia estimular tais reformas. Outra medida fortemente indicada por Banco Mundial (2013a) e Bruns e Luque (2015) foi o estabelecimento de standards que especifique as expectativas tanto ao nível do ensino quanto da aprendizagem sobre o que se deve saber e ser capaz de fazer, contribuindo, assim, para uma maior coerência entre diferentes aspectos essenciais da profissão docente, como a formaçáo inicial, desenvolvimento profissional e avaliação dos professores, desenvolvendo, como na apreensão de Decker (2015), a ideologia da padronização, que visa, em última instância, incidir na subjetividade e na atuação docente, e servir de base para a responsabilização e regulação desta ampla categoria profissional. 


\section{O que revelam as diretrizes do Banco Mundial referente à formaçáo docente?}

Após a exposição da agenda específica do BM para as políticas de formação de professores, podemos evidenciar e discutir, na forma de síntese, os principais eixos da reforma pretendida pelo Banco, encoberta pelo discurso afável da busca pelo desenvolvimento e do alívio da pobreza, trata-se da: inversão ideológica entre aquilo que seria determinante e determinado; o uso funcional à logica do capital da categoria aprendizagem; e o predomínio das pedagogias do aprender a aprender.

No que se refere à inversão ideológica entre educação e desenvolvimento socioeconômico, vale destacar a advertência de Lombardi (2005) sobre a inadequada tentativa de discutir a educação de forma abstrata, visto ser essa uma prática social organicamente vinculada à dinâmica que rege o modo de produzir a existência humana, logo, seria a forma de organizar a sociedade, a determinação fundamental de qualquer fenômeno no campo educativo.

Como explica Andery et al. (2007), a assunção desse pressuposto não significa, de modo algum, que as formas jurídicas, políticas, filosóficas, ou em termos marxianos, as "formas ideológicas", sejam uma reprodução mecânica da atividade material dos homens, mas somente que na rede de interferências recíprocas e multideterminada de fatores subjetivos e condiçóes materiais imbricadas no desenvolvimento do homem e da sua história, tem primazia a sua base econômica.

Portanto, ao analisar as elaboraçóes do BM para o campo educacional, identificamos diversas recorrências desta Organização Multilateral realizar aquilo que Shiroma e Evangelista $(2014,2015)$ têm designado de "inversão ideológica”, ideia que, em síntese, expressa um "deslocamento ideológico operado pela perspectiva hegemônica, qual seja, o de atribuir a origem das crises econômicas e dos problemas sociais à educação" (SHIROMA; EVANGELISTA, 2014, p. 13).

Como manifestação desse mecanismo de reprodução ideológica, questôes inerentes ao sistema capitalista, como o desemprego, a fome, a pobreza, a destruição da natureza e a guerra entre os povos, se resolveriam com ajustes nas abordagens educacionais, as quais deveriam privilegiar, a partir de então, conhecimentos e qualificaçôes adequadas às transformaçóes contemporâneas, voltadas às mudanças tecnológicas, ao desenvolvimento sustentável, à gestão ambiental responsável, à cidadania democrática e à cultura da paz. 
Nessa estrutura discursiva, a instituição escolar e os professores são usualmente responsabilizados náo apenas pelo sucesso dos estudantes de forma individualizada, mas pelo nível de desenvolvimento de toda a naçáo. Ao realizar esse movimento, o BM busca não somente deslocar a atenção da opinião pública dos problemas mais gerais da ordem do capital para a esfera educacional, como também tornar os sistemas educativos 'presas fáceis' para os pacotes de reformas que visam ajustar o processo de escolarização às novas exigências produtivas e de sociabilidade no marco do capitalismo.

Em se tratando de um campo de tensóes, Shiroma e Evangelista (2014) apontam para a necessidade da desconstrução desse "silogismo idealista" pela via da sua elucidação, refletindo sobre suas implicações para a escola e para os interesses da classe trabalhadora. Duarte (2008) também chama atenção para o imperativo de compreender o papel desempenhado pelos mecanismos de reprodução ideológica de uma formação societária específica, insistindo para aqueles que buscam a superação dessa sociedade não menosprezarem esses dispositivos como se fossem algo inofensivo, visto que o seu exame rigoroso "nos ajudará a criarmos formas de intervenção coletiva e organizada na lógica objetiva dessa formação societária” (DUARTE, 2008, p. 14).

No que diz respeito à dimensão da aprendizagem para o amoldamento educacional à lógica do capital, vale observar que o BM estabeleceu como centro da sua estratégia educacional para a década que está no fim (20112020) a máxima de uma Aprendizagem para todos (BANCO MUNDIAL, 2011). Entre as ideias-chave vinculadas à categoria da aprendizagem está aquela de que investir nos conhecimentos e competências das pessoas promoveria o desenvolvimento (BANCO MUNDIAL, 2011).

Como podemos apreender dessa elaboração, a aprendizagem tem se configurado bastante útil para buscar operar um conjunto de amoldamentos na esfera subjetiva, que assim denominamos: individualização da demanda por aprendizagem; responsabilização da escola e do professor; e a adjetivação da aprendizagem.

O primeiro seria o de individualizar a demanda por aprendizagem, tratando como se essa fosse uma questão de foro íntimo, isto é, os conhecimentos e qualificaçóes estão disponíveis a todos, restando ao indivíduo atomizado o entusiasmo pelo seu próprio desenvolvimento. Nessa lógica, o desemprego se transforma em questão de desqualificação e ausência de competências, enquanto o emprego precário ê concebido como escolhas malsucedidas dos sujeitos.

O segundo amoldamento, como expressão mais recorrente, tem sido a responsabilização da escola e, fundamentalmente, do professor, pela tarefa de 
gerar o estímulo pela aprendizagem no aluno; seria, portanto, o professor o "ingrediente fundamental", o "elemento sine qua non", o "preditor mais importante" para desencadear a inspiração necessária à aprendizagem. Até mesmo quando o BM se refere a uma ampla estratégia que envolva "todos pela aprendizagem” (BANCO MUNDIAL, 2018), é o professor que é deslocado para o centro das açôes; seja nas medidas de mobilização da comunidade escolar, ou de transformações na gestão escolar, ou ainda, de apoio aos estudantes, o foco de incidência comumente são os professores. Dessa forma, amplia-se a pressão exercida pela comunidade, efetiva-se novos mecanismos de regulação e produz-se novas demandas junto aos estudantes sem, contudo, corresponder à novas condiçóes de trabalho para os professores.

O terceiro amoldamento envolve a adjetivaçáo regularmente empregada à aprendizagem, isto é, que ela precisa ocorrer ao 'longo da vida'. É importante frisar que não temos desacordo com a premissa de que, realmente, a aprendizagem ocorra em todos os momentos da vida, a oposição, contudo, se faz no uso ideológico e nos resultados que se almeja com a utilização dessa assertiva. A retórica quase sempre se inicia pela caracterização de um mundo em mudança, imprevisível e volátil; argumenta-se que transformaçóes incorreram em todas as dimensóes da vida: cultura, tecnologia, condiçôes climáticas e, essencialmente, no mundo do trabalho, com este último se tornando irreconhecível, a ponto de todos os indivíduos necessitarem mudar e acompanhar o ritmo frenético das suas transformaçóes.

As recomendaçóes vão no sentido do alargamento e o reconhecimento das possibilidades de aprendizagem obtidas em outras esferas da vida, especificamente aquelas ligadas diretamente ao ramo produtivo, extrapolando, assim, o universo dos sistemas educacionais oficiais e abrindo novas oportunidades ao setor privado no 'mercado educacional'. No que se refere aos sistemas educativos, estes são convocados a se ajustarem à realidade cambiante de forma sistêmica, para isso, são denunciados enfaticamente como arcaicos e obsoletos. A mensagem é clara: aqueles sistemas, instituiçóes, sujeitos refratários à mudança estarão indo de encontro ao futuro das novas gerações e estarão obstaculizando o desenvolvimento da nação. $\mathrm{O}$ fim de tudo, a afamada aprendizagem que, devido à mutabilidade da vida, nunca se perfaz, contudo, esta seria a sua atribuição maior ante os propósitos das Organizaçóes Multilaterais - alimentar a inquietude da insegurança, veicular a inviabilidade da certeza e derrocar projetos históricos que se propugnem contrários à lógica do capital.

Por fim, quanto às pedagogias do aprender a aprender estarem no centro das proposições para a formação docente, as recorrências demonstram 
que entre as características fundamentais apontadas pelo BM para a formação de professores foi de que essa deveria ser específica, reiterativa e, fundamentalmente, direcionada à prática em sala de aula. Entre as competências ressaltadas, podemos mencionar o uso eficiente de estratégias e técnicas de ensino aplicadas e a capacidade de ensinar em salas de aulas diversas e com poucos recursos, respondendo às necessidades de aprendizagem de 'alunos desfavorecidos'. Sempre orientadas pela questão do custo-eficácia, tais opçóes se sustentam na forte recomendação de uma formação de caráter prático, no formato de treinamento/capacitação em serviço, com foco na instituição escolar, em detrimento da formação inicial, de feitio acadêmicoteórico, realizado pelas universidades.

Essas indicaçóes no campo da formação de professores por parte do BM estão relacionadas, no fundo, com o predomínio daquilo que Duarte (2003, 2008, 2010) tem denominado nos seus estudos como "pedagogias do aprender a aprender”. Segundo Duarte (2010), essas pedagogias têm ocupado uma quase total hegemonia do debate educacional nas duas últimas décadas, com destaque para o construtivismo, a pedagogia do professor reflexivo, a pedagogia das competências, a pedagogia dos projetos e a pedagogia multiculturalista (DUARTE, 2010).

Sobre os traços definidores dessas pedagogias, Duarte (2010) indica que, no geral, elas convergem na ausência da perspectiva de superação da sociedade capitalista; a negação da perspectiva de totalidade social; a assunção do relativismo, tanto em seu aspecto epistemológico, quanto cultural; a difusão de que o cotidiano do aluno deve ser a referência central para as atividades escolares, logo, só teria relevância o conhecimento que pode ser empregado para a resolução dos problemas da prática cotidiana; e a supervalorização do conhecimento tácito, cotidiano, pessoal, em detrimento do conhecimento científico, teórico e acadêmico.

No estudo Conhecimento tácito e conhecimento escolar na formação do professor, Duarte (2003) submeteu à crítica o trabalho de influentes nomes no campo da formação de professores, fundamentalmente, o do norte-americano Donald Schön, os quais integram essa tendência dominante de desvalorização do conhecimento científico/teórico/acadêmico nos estudos educacionais contemporâneos, em favor do conhecimento tácito, cotidiano, não científico. Radicalmente contrário a essa defesa, Duarte (2003) faz uso de um interessante excerto da produção do psicólogo russo Alexander Luria que esclarece os limites da alegação de reduzir o pensamento às margens das situaçóes cotidianas, a qual entendemos ser de suma importância reproduzila: 
Se as pessoas agrupam os objetos e definem palavras com base em experiências práticas, poder-se-ia esperar que a conclusão que tiram de uma premissa dada em um problema lógico dependeria também de sua experiência prática imediata. Isso dificultaria, e talvez até tornasse impossível, a aquisição de um novo conhecimento, de maneira discursiva e lógico-verbal. Tal mudança representaria a transição da consciência sensivel para a racional, fenômeno que os autores marxistas clássicos consideram um dos mais importantes da história humana. (LURIA, 1988, p. 52-53 apud DUARTE, 2003, p. 622, grifos do autor).

Portanto, conforme Duarte (2010) advoga, se o conhecimento tácito passa a ser o mais valorizado na escola, estamos diante da descaracterização do trabalho do professor e, consequentemente, da sua formação, visto que como explica Duarte (2010), se a formação de professores deve construir seus conhecimentos a partir das demandas da prática cotidiana, no pensamento que acompanha a ação, assim como as crianças e os jovens envolvidos no processo educativo, logo, "aprender a pensar e a tomar decisóes acertadas diante de situaçóes práticas problemáticas e imprevisíveis seria um dos maiores senão o maior objetivo da formação de professores" (DUARTE, 2010, p. 42).

Diante do aviltamento expresso nessa proposta, Duarte (2003) é taxativo quanto a necessidade da união e reação daqueles que não se conformaram frente ao "recuo da teoria", para tanto, como uma das dimensóes para esse enfrentamento, Duarte (2010) indica a necessidade de superação das concepçôes negativas em relação ao ensino como transmissão do conhecimento, em prol da afirmação do professor como mediador entre o aluno e o patrimônio intelectual mais desenvolvido da humanidade.

\section{Consideraçóes Finais}

Neste estudo buscamos apresentar novos elementos que caracterizam a intervenção singular do Banco Mundial no âmbito educacional, que como adverte Pereira (2010), além de emprestador financeiro é também formulador e veiculador de ideias políticas em matéria de desenvolvimento capitalista. Portanto, em que pese o abrandamento do discurso reformador, pautado na cantilena do desenvolvimento socioeconômico das naçóes periféricas e do alívio da pobreza, as evidências são claras: trata-se do ajustamento de uma estratégia maior que tem por fim a manutenção da hegemonia burguesa, assim 
como a intensificação do processo de exploração capitalista dos bens e serviços públicos.

Nesse plano abrangente, não é de se surpreender que a maior categoria do funcionalismo público seja conclamada para dirigir a transformação pleiteada para o Século XXI. A congeminação de uma série de iniciativas que buscam dar respostas simultâneas ao problema da quantidade e qualidade do pessoal docente para atender às reformas dos sistemas educacionais tem o seu real significado, isto é, que as mudanças atinjam crianças e jovens submetidos à escolarização, com o objetivo de potencializar as vias de reprodução das condiçốes técnicas e ético-políticas necessárias ao capital, como uma estratégia sobre a formação da força de trabalho atual e futura.

Para tanto, a Política de Formação de Professores, pautada na clássica fórmula custo-eficácia e em um modelo minimalista, com foco nos conhecimentos prático-instrumentais, é concebida e delineada por meios de diversos mecanismos regulatórios, na tentativa de vincular, como elos de uma cadeia sistêmica, o conjunto de açóes e agentes, em função de um projeto educativo e formativo orientado pela tradicional pedagogia do consenso, a qual no campo da formação de professores, se expressaria em um perfil de educador competente tecnicamente, mas completamente inofensivo politicamente.

\section{Referências}

ANDERY, M. A. P. A. et al. Para compreender a ciência: uma perspectiva histórica. Rio de Janeiro: Garamond, 2007.

BANCO MUNDIAL. World Development Report 1998/1999: Knowledge for Development. New York: Oxford University, 1998.

BANCO MUNDIAL. World Development Report 2007: Development and the Next Generation. Washington, DC: World Bank, 2006.

BANCO MUNDIAL. Aprendizagem para todos: investir nos conhecimentos e competências das pessoas para promover o desenvolvimento. Estratégia 2020 para a Educação do Grupo Banco Mundial. Resumo Executivo. Washington, DC: Banco Mundial, 2011.

BANCO MUNDIAL. What matters most for teacher policies: systems approach for better education results. Working Paper Series, Washington, DC, n. 4, abr. 2013. 
BANCO MUNDIAL. World Development Report 2018: Learning to Realize Education's Promise. Washington, DC: World Bank, 2018.

BRITO NETO, A. C. Política nacional de formação de professores no Brasil (2003-2016) como expressáo da governança global. 2018. Tese (Doutorado em Educação) -Programa de Pós-Graduação em Educação, Universidade Federal de Santa Catarina, Florianópolis, 2018. Disponível em: https://repositorio.ufsc.br/handle/123456789/193601. Acesso em: $11 \mathrm{dez}$. 2020.

BRUNS, B.; LUQUE. J. Professores excelentes: como melhorar a aprendizagem dos estudantes na América Latina e no Caribe. Washington, DC: Banco Mundial, 2015.

DECKER, A. I. A formação docente no projeto político do Banco Mundial (2000-2014). 2015. 234 f. Dissertação (Mestrado em Educação) Universidade Federal de Santa Catarina, Florianópolis, 2015.

DUARTE, N. Conhecimento tácito e conhecimento escolar na formação do professor (por que Donald Schön não entendeu Luria). Educação \& Sociedade, Campinas, v. 24, n. 83, p. 601-625, ago. 2003.

DUARTE, N. Sociedade do conhecimento ou sociedade das ilusóes? Quatro ensaios crítico-dialéticos em filosofia da educação. Campinas, SP: Autores Associados, 2008.

DUARTE, N. O debate contemporâneo das teorias pedagógicas. In: MARTINS, L. M.; DUARTE, N. Formação de Professores: limites contemporâneos e alternativas necessárias. São Paulo: Cultura Acadêmica, 2010. p. 33-49.

LEHER, R. Um novo senhor da educação? A política do Banco Mundial para a periferia do capitalismo. Outubro, Sáo Paulo, v. 1, n. 3, p. 19-30, 1999.

LOMBARDI, J. C. Educação, ensino e formação profissional em Marx e Engels. In: LOMBARDI, J. C.; SAVIANI, D. (orgs.). Marxismo e Educação: debates contemporâneos. Campinas: Autores Associados: HISTEDBR, 2005, p. $1-38$.

PEREIRA, J. M. M. O Banco Mundial como ator politico, intelectual e financeiro (1944-2008). Rio de Janeiro: Civilização Brasileira, 2010.

PRONKO, M. O Banco Mundial no campo internacional da educação. In: PEREIRA, J. M. M. PRONKO, M. A demolição de direitos: um exame das 
políticas do Banco Mundial para a educação e a saúde. Rio de Janeiro: EPSJV, 2014.

SHIROMA, E. O.; EVANGELISTA, O. Apresentação - luzes que desiluminam: uma análise dos slogans na política educacional. In: EVANGELISTA, O. (Org.). O que revelam os slogans na politica educacional. Araraquara, SP: Junqueira \& Marin, 2014. p. 11-20.

SHIROMA, E. O.; EVANGELISTA, O. Formação humana ou produção de resultados? Trabalho docente na encruzilhada. Revista Contemporânea de Educação, Rio de Janeiro, v. 10, n. 20, p. 89-114, 2015.

SHIROMA, E. O.; CAMPOS, R. F.; GARCIA, R. M. C. Decifrar textos para compreender a política: subsídios teórico-metodológicos para análise de documentos. Perspectiva, Florianópolis, v. 23, n.2, p. 427-446, jul./dez. 2005.

TORRES, R. M. Melhorar a qualidade da educação básica? As estratégias do Banco Mundial. In: TOMASI, L.; WARDE, M. J.; HADDAD, S. (Orgs.). O Banco Mundial e as Políticas Educacionais. 6 ed. São Paulo: Cortez, 2009. p. 125-193.

Recebido em: 28 ago. 2020

Aceito em: 15 dez. 2020 